\title{
No benefit of the combination therapy etanercept and methotrexate compared to etanercept mono therapy in juvenile idiopathic arthritis - a matched pair analysis
}

Heinrike Schmeling ${ }^{2 *}$, Gerd Horneff ${ }^{1}$

From 2011 Pediatric Rheumatology Symposium sponsored by the American College of Rheumatology Miami, FL, USA. 2-5 June 2011

\section{Purpose}

Etanercept has been approved in polyarticular juvenile idiopathic arthritis (JIA) patients refractory or intolerant to methotrexate. The objectives of the study were to evaluate safety and efficacy of Etanercept and Methotrexate combination therapy versus Etanercept mono therapy in JIA using a matched pair analysis.

\section{Methods}

A cohort of 1190 JIA patients enrolled in the German JIA Enbrel registry has been used for screening. Matching criteria included JIA subtype, gender, disease duration, use of corticosteroids, oligo- versus polyarthritis at therapy start and the sedimentation rate. Efficacy was determined using the PedACR 30/ 50 and 70 response criteria. Safety assessments were based on adverse events reports. The matched data at month 1, 3, 6, 12, 18 and 24 on treatment have been analyzed using the McNemar's test.

\section{Results}

87 JIA matching pairs with a total of 658 visits have been identified. No difference in PedACR 30/50/70 treatment response between mono and combination therapy has been found: month 1 : $73 \% / 61 \% / 33 \%$ vs. $70 \% / 61 \% / 33 \%$, month 3: $73 \% / 69 \% / 51 \%$ vs. $65 \% / 59 \% / 41 \%$; month $6: 82 \% /$ $77 \% / 59 \%$ vs. $83 \% / 72 \% / 59 \%$; month $12: 85 \% / 78 \% / 63 \%$ vs. $89 \% / 80 \% / 67 \%$; month $18: 77 \% / 73 \% / 69 \%$ vs. $89 \% / 81 \% / 77 \%$; month $24: 63 \% / 56 \% / 50 \%$ vs. $56 \% / 34 \% / 34 \%$. In the mono therapy group 18 patients (21\%) experienced 28 adverse events. Five of them have been reported as serious. In the combination group 19 patients (22\%) experienced 30 adverse events. Seven of them have been reported as serious. No infectious serious adverse events occurred in the mono therapy group compared to 3 in the combination group. Two malignancies have been observed in the combination group, none in the monotherapy group. Treatment has been discontinued in 29 patients on mono therapy (inefficacy $10 \%$, adverse events $8 \%$, remission $21 \%$, others $16 \%$ ) compared to 51 patients in the combination group (inefficacy $21 \%$, adverse events $8 \%$, remission $18 \%$, others $36 \%)$.

\section{Conclusion}

In contrast to the wide spread belief, combination treatment with Etanercept and Methotrexate did not offer a better outcome than treatment with Etanercept alone in JIA patients who previously have been treated ineffectively with methotrexate. However the rate of serious adverse events, especially serious infections was slightly increased.

\section{Disclosure}

Heinrike Schmeling: None; Gerd Horneff: Abbott Immunology Pharmaceuticals, 2, 5, Bristol-Myers Squibb, 5, Chugai, 5, Nycomed, 5, Pfizer Inc, 2, 5, Sandoz, 5.

\footnotetext{
Author details

${ }^{1}$ Asklepios Clinics, Sankt Augustin, Nordrhein-Westfalen, Germany. ${ }^{2}$ University of Calgary, Calgary, AL, Canada.
} 
doi:10.1186/1546-0096-10-S1-A59

Cite this article as: Schmeling and Horneff: No benefit of the

combination therapy etanercept and methotrexate compared to

etanercept mono therapy in juvenile idiopathic arthritis - a matched

pair analysis. Pediatric Rheumatology 2012 10(Suppl 1):A59.

Submit your next manuscript to BioMed Central and take full advantage of:

- Convenient online submission

- Thorough peer review

- No space constraints or color figure charges

- Immediate publication on acceptance

- Inclusion in PubMed, CAS, Scopus and Google Scholar

- Research which is freely available for redistribution

Submit your manuscript at 